\title{
Linfoma folicular de terceira pálpebra em um felino: Relato de caso de neoplasma raro associado à co-infecção viral por calicivírus, FIV e FeLV
}

Follicular lymphoma in the third eyelid in a feline: A case report of a rare neoplasm associated with co-infection viral by calicivirus, FIV and FeLV

Linfoma folicular del tercer párpado en un felino: reporte de un caso de neoplasia rara asociada a coinfección viral por calicivirus, FIV y FeLV

Luciana Aquini Fernandes Gil ORCID: https://orcid.org/0000-0002-4345-1632 Universidade Federal de Pelotas, Brasil E-mail: lafgil@hotmail.com

Helena Piúma Gonçalves ORCID: https://orcid.org/0000-0002-2289-598X Universidade Federal de Pelotas, Brasil

E-mail: helena.piuma@gmail.com

Katiellen Ribeiro das Neves ORCID: https://orcid.org/0000-0002-0180-222X Universidade Federal de Pelotas, Brasil E-mail: katiellenribeirodasneves@hotmail.com

Stefanie Bressan Waller ORCID: https://orcid.org/0000-0001-6719-1794 Universidade Federal de Pelotas, Brasil E-mail: waller.stefanie@yahoo.com.br

Nielle Versteg

ORCID: https://orcid.org/0000-0001-6912-0359 Universidade Federal de Pelotas, Brasil E-mail: nielle.versteg@gmail.com

Tábata Pereira Dias

ORCID: https://orcid.org/0000-0003-3537-5374 Universidade Federal de Pelotas, Brasil

E-mail: tabata_pd@yahoo.com.br

Gabriela Sanzo

ORCID: https://orcid.org/0000-0002-6346-8335 Universidade Federal de Pelotas, Brasil

E-mail: gabi_sanzo@hotmail.com

Ana Raquel Mano Meinerz

ORCID: https://orcid.org/0000-0001-7278-6872 Universidade Federal de Pelotas, Brasil

E-mail: rmeinerz@bol.com.br

Fabiane Borelli Grecco

ORCID: https://orcid.org/0000-0002-3996-315X Universidade Federal de Pelotas, Brasil E-mail: fabianegrecco18@gmail.com

Marlete Brum Cleff

ORCID: https://orcid.org/0000-0001-9082-5185 Universidade Federal de Pelotas, Brasil E-mail: marletecleff@gmail.com

\begin{abstract}
Resumo
O linfoma representa cerca de $80 \%$ dos tumores hematopoiéticos nos felinos, sendo diagnosticado através de análises citopatológicas, histopatológicas e imunohistoquímicas. A classificação segue a localização anatômica (gastrointestinal, mediastínico, nodal e extranodal) e o grau (baixo, intermediário e alto). Assim, objetivou-se relatar um caso raro de linfoma em felino doméstico, macho, 8 anos, não vacinado, não castrado, semi-domiciliado e oriundo de comunidade socialmente vulnerável. Ao exame clínico, o felino apresentou condição corporal magro, apatia, desidratação, mucosas hipocoradas, linfonodos submandibulares e retrofaríngeos reativos, secreção ocular bilateral, exoftalmia, lesão e edema na face, prolapso de terceira pálpebra, nódulos cutâneos difusos e evidência de dor. A partir de exames laboratoriais, foi confirmado que o felino era positivo para FIV, FeLV e calicivirus, foram identificados
\end{abstract}


fungos e bactérias na amostra ocular, no hemograma observou-se anemia, trombocitopenia, leucopenia e linfopenia. O paciente veio a óbito após a abordagem inicial, sem que tenha sido estabelecido protocolo terapêutico para o tratamento da neoplasia. O diagnóstico após exame histopatológico do tumor foi linfoma folicular de terceira pálpebra, com a presença de células linfocíticas neoplásicas com pleomorfismo moderado e escasso citoplasma distribuídas em frouxo tecido conjuntivo. O linfoma folicular em terceira pálpebra de felinos é raro, entretanto, é provável que animais semi-domiciliados, sem imunização vacinal sejam mais propensos a desenvolver este tipo de neoplasia por ação oncogênica viral associada a co-infecção por FIV e FeLV.

Palavras-chave: Linfoma folicular; Tumor; Felino; Retroviroses; Oftalmologia.

\begin{abstract}
Lymphoma represents about $80 \%$ of hematopoietic tumors in felines, being diagnosed through cytopathological, histopathological and immunohistochemical analyses. Classification follows anatomical location (gastrointestinal, mediastinal, nodal and extranodal) and grade (low, intermediate and high). We aimed to report a rare case of lymphoma in a domestic feline, male, 8 years old, not vaccinated, not neutered, semi-domiciled and from a socially vulnerable community. Upon clinical examination, the feline showed thin body condition, apathy, dehydration, pale mucosa, reactive submandibular and retropharyngeal lymph nodes, bilateral ocular secretion, exophthalmia, facial lesion and edema, third eyelid prolapse, diffuse skin nodules and evidence of pain. Laboratory tests confirmed that the feline was positive for feline immunodeficiency virus (FIV), feline leukemia virus (FeLV) and calicivirus, fungi and bacteria were identified in the eye sample, the blood count showed anemia, thrombocytopenia, leukopenia and lymphopenia. The patient died after the initial approach, without establishing a therapeutic protocol to treat the neoplasm. The histopathological diagnosis after tumor examination was follicular lymphoma in the third eyelid, with the presence of neoplastic lymphocytic cells with moderate pleomorphism and sparse cytoplasm distributed in loose connective tissue. Follicular lymphoma in the third eyelid of felines is rare, however, it is likely that semi-domiciled animals without vaccine immunization are more likely to develop this type of neoplasm due to viral oncogenic action associated with co-infection with FIV and FeLV.
\end{abstract}

Keywords: Folicular lymphoma; Tumor; Feline; Retroviruses; Ophthalmology.

\title{
Resumen
}

El linfoma representa alrededor del $80 \%$ de los tumores hematopoyéticos en felinos, siendo diagnosticado mediante análisis citopatológico, histopatológico e inmunohistoquímico. La clasificación sigue la ubicación anatómica (gastrointestinal, mediastínica, ganglionar y extraganglionar) y el grado (bajo, intermedio y alto). Así, el objetivo fue reportar un caso raro de linfoma en un felino doméstico, macho, raza indefinida, de 8 años, no vacunado, no castrado, semi-domiciliado y de una comunidad socialmente vulnerable. En el examen clínico, el felino mostró condición corporal delgada, apatía, deshidratación, mucosa pálida, ganglios linfáticos submandibulares y retrofaríngeos reactivos, secreción ocular bilateral, exoftalmia, lesión y edema facial, prolapso del tercer párpado, nódulos cutáneos difusos y evidencia de dolor. A partir de pruebas de laboratorio, se confirmó que el felino fue positivo para virus de inmunodeficiencia felina (VIF), virus de leucemia felina (FeLV) y calicivirus, se identificaron hongos y bacterias en la muestra de ojo, se observó anemia en el hemograma, trombocitopenia, leucopenia y linfopenia. El paciente falleció tras el abordaje inicial, sin que se hubiera establecido un protocolo terapéutico para el tratamiento de la neoplasia. El diagnóstico tras el examen histopatológico del tumor fue de linfoma folicular del tercer párpado, con presencia de células linfocíticas neoplásicas con pleomorfismo moderado y escaso citoplasma distribuido en tejido conectivo laxo. El linfoma folicular en el tercer párpado de los felinos es raro, sin embargo, es probable que los animales semidomiciliados sin vacunación sean más propensos a desarrollar este tipo de neoplasia por acción viral oncogénica asociada a coinfección con FIV y FeLV.

Palabras clave: Linfoma folicular; Tumor; Felino; Retrovirus; Oftalmología.

\section{Introdução}

Os linfomas representam um grupo de tumores fenotipicamente e geneticamente heterogêneo, que se originam a partir de linfócitos (Valli et al., 2017). Esse grupo tumoral representa cerca de $80 \%$ dos tumores hematopoiéticos em felinos, acometendo principalmente os linfonodos, além de outros órgãos e tecidos como baço, amígdalas, timo, trato gastrointestinal, sistema nervoso, trato respiratório, pele e plano nasal (Valli et al., 2017).

De acordo com a localização anatômica e manifestações clínicas predominantes, pode ser classificado em linfoma entérico ou alimentar, mediastínico e cutâneo (Valli et al., 2017). O termo linfoma extranodal é utilizado para designar tumores confinados a locais diferentes dos linfonodos, trato gastrointestinal e mediastino, e a designação multicêntrico descrita quando são acometidos diversos sítios anatômicos. Porém, esse termo deve ser associado a características celulares, fenotípicas, grau e 
disseminação (Valli et al., 2017). Tratando-se especificamente da espécie felina, os linfomas entérico, mediastínico, multicêntrico e extranodal são os mais prevalentes (Valli et al., 2017).

O prognóstico dos linfomas varia de acordo com o tipo e tamanho das células neoplásicas, grau de linfocitose ou linfopenia (Valli et al., 2017), sendo que em felinos está relacionado a presença de outras comorbidades adjacentes (Vail, 2013), como a co-infecção nos gatos com os Vírus da Leucemia Felina (FeLV) e Vírus da Imunodeficiência Felina (FIV) (Hartmann, 2006).

Os felinos podem apresentar linfoma espontaneamente e por ação oncogênica viral, sendo que o FIV pode exercer um papel oncogênico direto (Hartmann, 2012), enquanto o FeLV tem sido o principal agente viral envolvido, embora a prevalência por essa associação tenha diminuído ao longo dos anos, em decorrência da implementação de programas de vacinação e manutenção de felinos domiciliados (Little et al., 2020). No entanto, a taxa de gatos infectados com retroviroses permanece alta no Brasil (Teixeira et al., 2019; Mello et al., 2019; Gonçalves et al., 2021), especialmente em regiões caracterizadas por altas taxas populacionais de felinos com vida livre e não vacinados (Little et al., 2020; Sykes 2014; Sykes \& Hartmann, 2014; Gonçalves et al., 2021). Em humanos, o linfoma não-Hodgkin é um dos mais comuns e está frequentemente associado ao vírus da imunodeficiência adquirida, isto é, HIV (Mota et al., 2021), afetando o status imunológico do hospedeiro, semelhantemente ao que ocorre em felinos infectados pelo FIV.

O diagnóstico de linfomas foliculares em gatos é um desafio, sendo que a expressão de Bcl-2, frequentemente observada em linfomas foliculares humanos, não se mostrou útil para este tipo de linfoma em felinos (Henrich et al., 2019). Frente ao exposto, o estudo objetivou relatar um caso atípico de linfoma folicular de terceira pálpebra em felino, bem como discutir a associação com outras comorbidades, os aspectos clínicos, laboratoriais, epidemiológicos e anatomopatológicos do caso.

\section{Metodologia}

O presente trabalho relata um caso clínico em um felino pelo método descritivo e qualitativo, cuja abordagem direta consistiu no recolhimento de dados do estudo para acesso a registros de exames complementares, conforme descrito por Pereira et al. (2018). A coleta de dados e suas análises foi feita mediante registros de exames realizados durante o atendimento clínico veterinário, o qual ocorreu no Ambulatório Veterinário Ceval, anexo ao Hospital de Clínicas Veterinária, da Universidade Federal de Pelotas (UFPel, Pelotas/RS, Brasil). O presente relato foi autorizado pelo tutor do referido animal para fins educacionais.

\section{Relato de Caso Clínico}

Foi atendido no Ambulatório Veterinário Ceval, da Universidade Federal de Pelotas (UFPel) um felino, sem raça definida (SRD), macho, 8 anos, pesando 3,2 kg, com histórico de desaparecimento, ficando cerca de um mês fora do domicílio. O paciente não era esterilizado e nunca havia recebido vacinação.

Ao exame clínico do felino, foram evidenciadas condição corporal magro, apatia, desidratação moderada, mucosas hipocoradas, linfonodos submandibulares e retrofaríngeos reativos bilateralmente. Ainda, apresentava secreção mucosa ocular bilateral e exoftalmia. Também foi detectada extensa ferida na lateral da face, prolapso de terceira pálpebra no olho direito, além de edema em face, abrangendo principalmente a face direita, estendendo-se até a cabeça e região cervical, com evidência de dor a palpação nas regiões acometidas. Ainda, apresentava nódulos cutâneos difusos, de variados tamanhos, de consistência firme e aderidos ao tecido subcutâneo, na extensão da coluna vertebral. No ambulatório, o felino recebeu terapia de suporte inicial, sendo aplicado fármacos para controle de dor e encaminhamento para o Hospital de Clínicas Veterinária (HCV - 
UFPel), onde permaneceu internado. Foram coletadas amostras do tumor localizado na face direita, pela técnica de citologia aspirativa por agulha fina (CAAF). Os resultados revelaram presença de linfócitos, neutrófilos e eritrócitos na citologia, sendo este resultado inconclusivo. Durante a consulta ainda foram coletadas amostras sanguíneas para realização de hemograma, e os resultados estão dispostos na Tabela 1 .

Tabela 1 - Resultados do hemograma realizado no paciente felino durante o internamento no HCV-UFPel.

\begin{tabular}{ccc}
\hline $\begin{array}{c}\text { Parâmetro analisado } \\
\text { no paciente }\end{array}$ & Resultados do paciente & Valores de referência* \\
\hline Hemácias & $3,47 \times 10^{6} / \mathrm{mm}^{3}$ & $5-10 \times 10^{6} / \mathrm{mm}^{3}$ \\
Hemoglobina & $7,7 \mathrm{~g} / \mathrm{dl}$ & $8-15 \mathrm{~g} / \mathrm{dl}$ \\
Hematócrito & $24,8 \%$ & $24-45 \%$ \\
VCM & $71,5 \mathrm{fl}$ & $39-55 \mathrm{fl}$ \\
CHCM & $31,0 \%$ & $31-35 \%$ \\
Plaquetas & $90 \times 10^{3} / \mathrm{mm}^{3}$ & $300-800 \times 10^{3} / \mathrm{mm}^{3}$ \\
Leucócitos & $2.900 / \mathrm{mm}^{3}$ & $5.500-19.500 / \mathrm{mm}^{3}$ \\
Segmentados & $1.740 / \mathrm{mm}^{3}$ & $2.500-12.500 / \mathrm{mm}^{3}$ \\
Bastonetes & $87 / \mathrm{mm}^{3}$ & $0-300 / \mathrm{mm}^{3}$ \\
Linfócitos & $986 / \mathrm{mm}^{3}$ & $1.500-7.000 / \mathrm{mm}^{3}$ \\
\hline
\end{tabular}

*Kaneco (1997); Jain (1993). Fonte: Autores.

Os índices hematimétricos de hemácias e hemoglobina encontravam-se reduzidos, caracterizando um quadro anêmico. Nas observações do exame, constavam a presença de anisocitose (+++) e de metarrubrícitos (12\%), sugerindo a presença de células imaturas da linhagem eritrocitária. Os valores de VCM e CHCM do paciente, determinaram uma anemia macrocítica normocrômica. As plaquetas mostraram-se baixas, indicando uma trombocitopenia considerável. O leucograma resultou em intensa leucopenia, decorrente de um quadro neutropênico. Os valores de bastonetes estavam dentro da normalidade para a espécie, o que descartou naquele momento a presença de um desvio a esquerda. O paciente apresentava-se linfopênico, com as demais células da série branca dentro dos padrões fisiológicos para a espécie felina.

Amostras oftálmicas foram coletadas através de swabs para exame bacteriológico, fúngico e viral. A cultura fúngica demonstrou crescimento de fungos sapróbios Aspergillus sp., Penicillium sp., Mucor racemosus, Mycelia sterilia, enquanto o exame de microscopia direta evidenciou presença acentuada de células inflamatórias. Já, na amostra enviada para bacteriologia, identificou-se Staphylococcus sp. coagulase negativa na cultura. Quanto ao diagnóstico viral, foi detectada amostra positiva para Calicivirus e negativa para Herpesvirus. Foram realizados os testes rápidos para diagnóstico de FIV e FeLV (Alere $@$, São Paulo, Brasil), resultando positivo para ambas as retroviroses. Durante a internação, foram prescritos tramadol (50 mg/ml, na dose de 0,25ml, IV ou SC, BID), dipirona (500 mg/ml, na dose de 0,2 ml, IV ou SC, BID), amoxicilina $(20 \mathrm{mg} / \mathrm{kg})$, ranitidina $(25 \mathrm{mg} / \mathrm{ml}$, na dose de $0,35 \mathrm{ml}$, IV ou SC, TID), colírio de tobramicina (1 gota, QID) e aminofilina $(4 \mathrm{mg} / \mathrm{kg}, \mathrm{IV}, \mathrm{SID})$.

Como medidas de suporte ao paciente, inicialmente foi administrada fluidoterapia com ringer e posteriormente manejo dietético com ração pastosa (3 vezes ao dia). Entretanto, o paciente iniciou com quadro neurológico, apresentando pedaleio, rotação de cabeça e convulsão focal, vindo a óbito após 3 dias de hospitalização.

Autorizado pelo tutor, o cadáver foi submetido à necropsia e exame anatomopatológico. Segundo a descrição macroscópica do laudo anatomopatológico, o cadáver apresentava-se caquético, com aumento de volume facial, na 
musculatura do masseter e região cervical em ambas as faces; apresentava nódulos cutâneos difusos, e havia uma massa que ocasionava o prolapso de terceira pálpebra (Figura 1) e estava comprimindo o nervo ótico. Abundantes hidrotórax e piotórax e herniação do cerebelo também foram observadas.

Figura 1 - Aspecto macroscópico do linfoma de terceira pálpebra em felino. Massa protuída e esbranquiçada envolvendo a terceira pálpebra (a); visão posterior da massa (b).

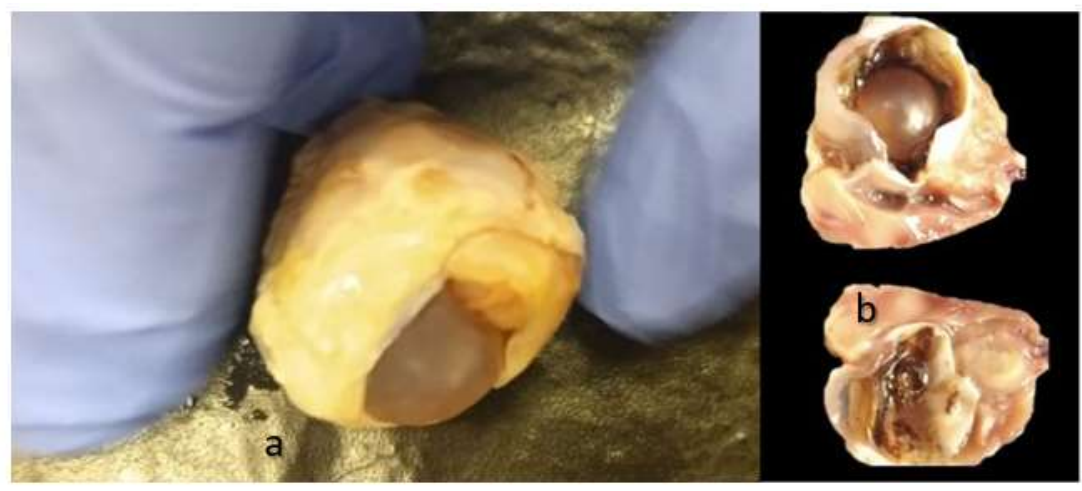

Fonte: Autores.

Ao exame microscópico da massa que envolvia a terceira pálpebra (Figura 2), observou-se infiltração de linfócitos neoplásicos com pleomorfismo nuclear moderado e escasso citoplasma, arranjadas em padrão folicular e apoiadas sobre frouxo tecido conjuntivo.

Figura 2 - Aspecto microscópico de massa constituída de células arredondadas de múltiplos tamanhos que invadiam e comprimiam o nervo ótico, presença de infiltração de linfócitos com pleomorfismo nuclear moderado e escasso citoplasma. Hematoxilina-Eosina aumentos de 5 (A), 10 (B) e 40× (C) respectivamente.

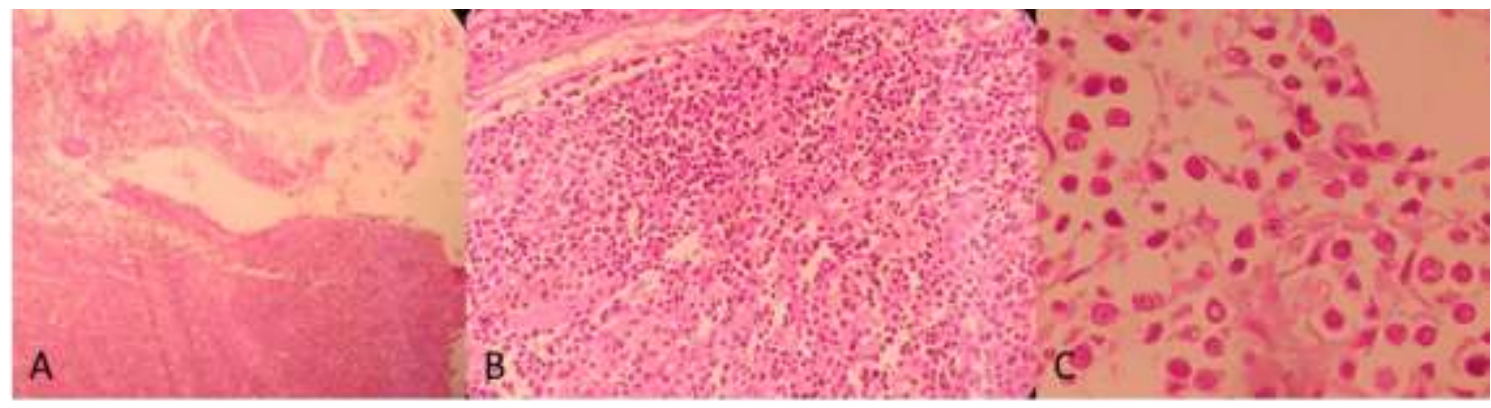

Fonte: Autores.

Os nódulos cutâneos exibiam edema afastando as fibras de colágeno dermais, infiltrado inflamatório mononuclear ao redor dos vasos sanguíneos, configurando dermatite histiolinfocitária perivascular acentuada. Ainda, havia broncopneumonia fibrino necrótica e pleurite fibrinosa. O diagnóstico da massa palpebral foi de linfoma folicular de terceira pálpebra. O resumo dos procedimentos e exames realizados no paciente felino e principais resultados estão apresentados na Figura 3 . 
Figura 3 - Representação gráfica dos procedimentos, exames realizados e principais resultados obtidos a partir das análises de amostras obtidas do felino.

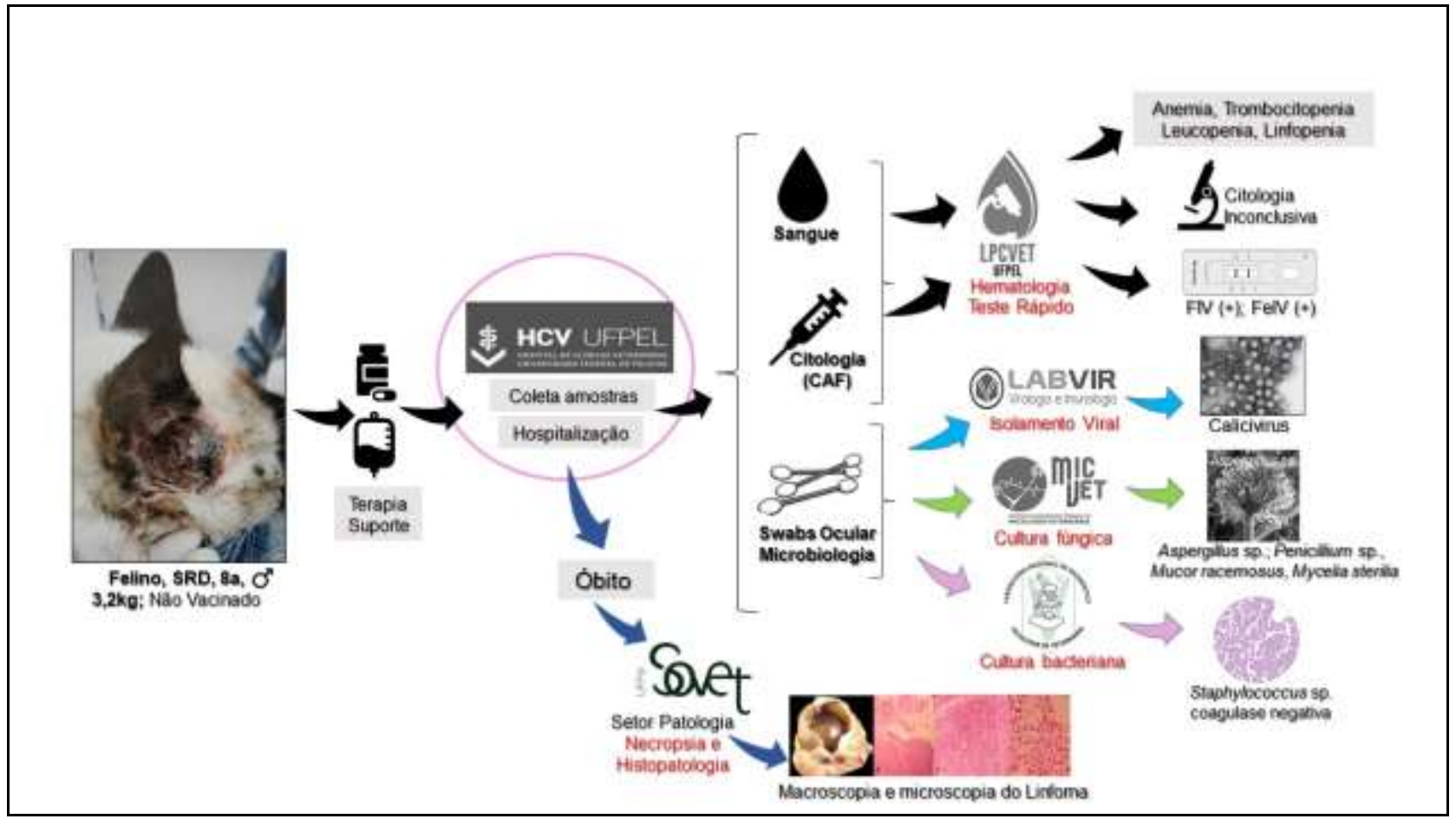

Fonte: Autores.

\section{Discussão}

O paciente estudado era um felino não vacinado, não castrado e semi-domiciliado, oriundo de comunidade socialmente vulnerável, onde convivia livremente e mantinha contato com outros gatos. Conforme dados obtidos através da anamnese, o mesmo ficou um período desaparecido, retornando com visível perda de condição corporal. Durante a avaliação do paciente, este foi positivo para as retroviroses FIV e FeLV. A condição de vida do mesmo provavelmente favoreceu a infecção às retroviroses, uma vez que os felinos errantes, de vida livre ou com acesso a rua são mais propensos a se contaminar através de outros animais infectados por meio da saliva, pelos hábitos de higiene ou pelo uso em comum de vasilhas e outros fômites (Zanutto et al., 2011; Teixeira et al., 2019), ou ainda através mordeduras e arranhaduras (Little et al., 2020).

Com relação aos sintomas apresentados pelo felino na consulta, sabe-se que, em animais com FeLV, os sinais são atribuídos às síndromes clínicas diversas, sendo que o paciente apresentava mucosas pálidas, dispnéia, letargia, anorexia e emagrecimento progressivo, conforme descrito na literatura (Little et al., 2020). Após a exposição via oronasal, o FeLV multiplica-se nos linfonodos, medula óssea, baço e glândulas salivares, podendo cursar com imunossupressão, além de várias afecções associadas, como desordens imunomediadas, hematopoiéticas, reprodutivas, neuropatias, e ainda, infecções secundárias.

O paciente resultou positivo para o FIV também, o que poderia contribuir para os sinais clínicos, já que o vírus pode levar a manifestações inespecíficas como letargia, anorexia, perda de peso, pirexia, linfadenopatia e linfopenia (Little et al., 2020; Teixeira et al., 2019). Em adição, o FIV promove degeneração progressiva do sistema imunológico, semelhante a que ocorre na Aids em humanos (Teixeira et al., 2019). Após a viremia primária, os gatos com FIV podem permanecer assintomáticos por anos, aparentemente saudáveis; todavia, a imunossupressão é comum, predispondo-os a infecções secundárias recorrentes e risco aumentado de neoplasias (Hartmann, 2011; Little et al., 2020; Teixeira et al., 2019). Ainda, o desenvolvimento de linfomas pode ocorrer, seja uma consequência direta da imunossupressão promovida pelo FIV ou devido à 
redução de linfócitos T CD4 (Hartmann, 2012). Os estudos ainda ressaltam a presença de sinais neurológicos em felinos com retroviroses, que podem ser observados em pequenas proporções, como anormalidades psicomotoras, agressão, anisocoria e convulsão (Sykes, 2014; Little et al., 2020), destacando que muitos desses sinais foram detectados no paciente descrito.

O paciente felino não havia recebido nenhuma imunização e, além de FIV e FeLV apresentava-se infectando com calicivírus felino (FVC). O FVC é responsável por infecções no trato respiratório superior, febre, anorexia, conjuntivite, secreção ocular e oronasal, além de estar envolvido no complexo gengivite estomatite linfoplasmocítica, uma grave síndrome inflamatória que acomete a cavidade oral (Radford et al., 2009; Hou et al., 2016). O vírus é altamente contagioso, com alta mortalidade, e acomete principalmente animais adultos, sendo transmitido pelo contato direto (Radford et al., 2009; Hou et al., 2016). Algumas cepas de FVC são altamente patogênicas, ocasionando doença sistêmica, caracterizada por síndrome de resposta inflamatória sistêmica, coagulação intravascular disseminada, vasculite, necrose e falência de múltiplos órgãos, com altas taxas de mortalidade (Radford et al., 2009; Foley et al., 2006), o que justifica a gravidade do caso acompanhado. Em relação a Staphylococcus sp. e fungos identificados na amostra oftálmica, estes agentes podem estar presentes na microbiota conjuntival de gatos domésticos de forma comensal e não patogênica, apresentando caráter oportunista (Souza et al., 2010; Samuelson et al., 1984; Büttner et al., 2019).

O hemograma do paciente revelou anemia macrocítica normocrômica com presença de células imaturas. Segundo Vail (2007), todos os linfomas em felinos podem desencadear infiltração na medula óssea, desenvolvendo alterações no eritrograma, especialmente anemias e, nas contagens leucocitárias. Destaca-se que o paciente apresentava outras afecções, e que a anemia é um dos achados mais frequentes em felinos com FeLV (Hartmann, 2011; Stützer et al., 2010), sendo também esperadas alterações leucocitárias, como neutropenia e linfopenia, que também foram observadas. A anemia pelo FeLV pode também ocorrer devido a infiltração neoplásica na medula óssea, ou ainda, por uma anemia hemolitica imunomediada devido à expressão de antígenos na superfície das hemácias (Hartmann, 2012a). Ainda, a infecção pelo FeLV tipo C geralmente está associada à existência de anemia grave com ausência de reticulócitos, enquanto as demais células permanecem dentro dos valores de referência (Linenberger \& Shelton, 1995). Ressalta-se que o esfregaço sanguíneo do felino apresentava indícios de resposta medular, com a presença de policromasia e anisocitose, no entanto, não foi realizada a contagem de reticulócitos, não sendo possível afirmar esta condição.

Ainda, sobre a relação da FeLV com os achados no hemograma do paciente, foi detectada linfopenia, que poderia ocorrer devido a replicação viral nos linfócitos, causando destruição das células CD4+ e CD8+ (Lutz et al., 2009). A neutropenia, por sua vez, pode ser resultante da infecção direta dos precursores dos neutrófilos da medula óssea (Hartmann, 2012a). O paciente apresentava considerável trombocitopenia, com valores de $90 \times 10^{3} / \mathrm{mm}^{3}$ (referência $300-800 \times 10^{3} / \mathrm{mm}^{3}$ ), alteração que pode estar diretamente relacionada a infecção pelo FeLV (Hartmann, 2011; Little et al., 2020). No entanto, vale lembrar que as alterações observadas no hemograma do paciente, podem também sofrer influência da infecção paralela do vírus da FIV, que desencadeia com frequência quadro anêmico, trombocitopênico, além de leucopênico, especialmente nas fases sintomáticas da retrovirose (Sykes, 2014).

Diante da gravidade do quadro clínico e às comorbidades do paciente (FIV, FeLV e calicivirose), o felino veio a óbito após três dias da abordagem inicial, não sendo estabelecido nenhum protocolo terapêutico específico para o neoplasma. Após a necropsia e ao exame microscópico histopatológico da terceira pálpebra, observou-se células linfocíticas neoplásicas com pleomorfismo moderado e escasso citoplasma, distribuídas sobre frouxo tecido conjuntivo, diagnosticando o tumor como linfoma folicular de terceira pálpebra, cuja massa comprimia o nervo ótico.

Na espécie felina, os tumores palpebrais e de terceira pálpebra ou da glândula, são considerados incomuns, e os relatos de linfomas de conjuntiva ocular em felinos são escassos. Holt et al. (2006) descreveram a neoplasia linfoide em conjuntiva palpebral de felino. Posteriormente no Reino Unido, foi avaliada a resposta terapêutica e prognóstico para linfoma 
extranodal em 110 gatos, e destes, apenas 5 animais apresentavam a forma ocular da neoplasia (Taylor et al., 2009). Recentemente Alves (2018), descreveu caso de linfoma conjuntival extranodal em felino, demonstrando raras células multinucleadas, revelando linfoma linfocítico de baixo grau/pequenas células, sendo que costumam apresentar caráter maligno e grande potencial de invasibilidade (Sila, 2011; Dees et al., 2015). A ocorrência de neoplasias palpebrais conjuntivais, pode ser atribuída à presença de tecido linfoide associado a mucosa (MALT) no local (Daleck et al., 2008) e estes, já foram relatadas em cães (Hong et al., 2011) porém, em felinos, não há relatos (Dees et al., 2015), sendo o presente relato inédito.

O linfoma origina-se principalmente nos linfonodos, e de forma menos comum, em outros sítios anatômicos (Mello et al., 2019; Valli et al., 2017). A presença de outras comorbidades, especialmente as retrovirais (FIV, FeLV), podem ter contribuído para ocorrência de linfoma atípico. Gatos infectados por FeLV apresentam probabilidade de aproximadamente 62 vezes maior de desenvolver linfoma, enquanto a infecção simultânea por FIV e FeLV aumenta em cerca de 80 vezes o risco de desenvolvimento da neoplasia (Mello et al., 2019; Hartmann, 2012). Diferente deste relato, os linfomas relacionados ao FeLV em geral são multicêntricos ou mediastinais e acometem gatos jovens; já, em associação com o FIV, geralmente são linfomas de células B, de alto grau de malignidade (Valli et al., 2017). Entretanto, o vírus FeLV tem sido considerado o mais significativo vírus indutor de tumores em felinos (Hartmann, 2006; Matesco et al., 2013; Pereira et al., 2017).

\section{Conclusão}

O desenvolvimento de linfoma folicular felino de localização em terceira pálpebra é uma condição rara e, pode ocorrer especialmente em animais de vida semi-domiciliada sem protocolos vacinais que estão propensos a infecções virais concomitantes. O presente relato alerta para a importância do diagnóstico precoce de linfoma e estabelecimento de medidas sanitárias em animais de comunidades em vulnerabilidade social. Como estratégias futuras para o caso exposto, sugere-se a realização de projetos sociais, envolvendo os profissionais e acadêmicos em Medicina Veterinária com a população, onde há maior incidência de animais peri-domiciliados ou de vida livre, a fim de minimizar a exposição a patógenos de potencial risco à saúde animal.

\section{Referências}

Alves, B. G. (2018). Linfoma conjuntival linfocítico de imunofenótipo T em um felino - relato de caso. UFPB - Trabalho de conclusão de curso.

Büttner, J. N., Schneider, M., Csokai, J., Müller, E. \& Eule, J. C. (2019) Microbiota of the conjunctival sac of 120 healthy cats. Veterinary Ophthalmology, 22(3), 328-336.

Daleck, R. C., Calazans G. S. \& Nardi, A. B. (2008) Linfomas. In: C. R. Daleck, A. D. Nardi. \& S. Rodaski (Ed.), Oncologia em cães e gatos (pp. 481-502). São Paulo, Roca.

Dees, D. D., Schobert, C. S., Dubielzig, R. R. \& Stein, T. J. (2015). Third eyelid gland neoplasms of dogs and cats: a retrospective histopathologic study of 145 cases. Veterinary Ophthalmology, 19(2), 138-143.

Foley, J., Hurley, K., Pesavento, P. A., Poland, A. \& Pedersen, N. C. (2006) Virulent systemic feline calicivirus infection: local cytokine modulation and contribution of viral mutants. Journal of Feline Medicine and Surgery, 8(1), 55-61.

Gonçalves, H. J., Ferraz, C. M., Hiura, E., Herzog, L. G., Pucheta, A. N., Ferreira, L. C., Vilela, V. L. R. \& Braga, F. R. (2021) Prevalence of Feline Leukemia Virus (FeLV) and main hematological changes in domestic cats in Vila Velha, Espírito Santo. Research, Society and Development, 10(6), 1-8.

Hartmann, K. (2006) Feline leukemia virus infection. In: C. E. Greene (Ed.), Infectious diseases of the dog and cat (3a ed., pp. 105-131). St. Louis: Elsevier.

Hartmann, K. (2011) Clinical aspects of feline immunodeficiency and feline leukemia virus infection. Veterinary Immunology and Immunopathology, 143(34), 190-201.

Hartmann, K. (2012) Clinical aspects of Feline Retroviruses: A Review. Viruses, 4(11), 2684-2710. 10.3390/v4112684.

Henrich, M., Bauknecht, A., Hecht \& W. Manfred Reinacher. (2019) Lack of Bcl-2 expression in feline follicular lymphomas. Journal of Veterinary Diagnostic Investigation, 31(6), 809-817.

Holt, E., Goldschmidt, M.H. \& Skorupski, K. (2006) Extranodal conjunctival Hodgkin's-like lymphoma in a cat. Veterinary Ophthalmology, 9(3): 141-144. 
Research, Society and Development, v. 10, n. 8, e53710817640, 2021

(CC BY 4.0) | ISSN 2525-3409 | DOI: http://dx.doi.org/10.33448/rsd-v10i8.17640

Hong, I.-H., Bae, S.-H., Lee, S.-G., Park, J.-K., Ji, A.-R., Ki, M.-R. \& Jeong, K.-S. (2011). Mucosa-associated lymphoid tissue lymphoma of the third eyelid conjunctiva in a dog. Veterinary Ophthalmology, 14(1), 61-65.

Hou, J., Sánchez-Vizcaíno, F., Mcgahie, D., Lesbros, C., Almeras, T., Howarth, D. \& Radford, A. D. (2016) European molecular epidemiology and strain diversity of feline calicivirus. The Veterinary Record, 178(5), 114.

Jain, N. C. (1993) Essentials of Veterinary Hematology. Lea \& Febiger.

Kaneko, J. J., Harvey, J. W. \& Bruss, M. L. (1997) Clinical Biochemistry of Domestic Animals (5th ed.). Academic Press.

Levy, J., Crawford, C., Hartmann, K., Hofmann-Lehmann, R., Little, S., Sundahl, E. \& Thayer, V. (2008) American Association of Feline Practitioners Feline Retrovirus Management Guidelines. Journal of Feline Medicine and Surgery, 3, 300-316.

Linenberger, M. L. \& Shelton, G. H. (1995) Hematologic abnormalities associated with retroviral infections in the cat. Seminars in Veterinary Medicine and Surgery, 10(4), 220-233.

Little, S., Levy, J., Hartmann, K., Hofmann-Lehmann, R., Hosie, M., Olah, G. \& Denis, K. S. (2020) AAFP Feline Retrovirus Testing and Management Guidelines. Journal of Feline Medicine and Surgery, 22(1), 5-30.

Lutz, H., Addie, D., Belak, S., Boucraut-Baralon, C., Egberink, H., Frymus, T., Gruffydd-Jones, T., Hartmann, K., Hosie, M. J., Lloret, A., Marsilio, F., Pennisi, M.G., Radford, A.D., Thiry, E., Truyen, U. \& Horzinek, M.C. (2009) Feline Leukaemia: ABCD Guidelines on Prevention and Management. Journal of Feline Medicine and Surgery, 11, 565-574.

Matesco, V. C., da Costa, F. V. A., Rolim, V. M. \& Sonne, L. (2013) Acute and fatal presentation of feline leukemia virus infection and FeLV-associated diseases in a cat: case report. Acta Veterinaria Brasilica, 7(1), 223-225.

Mello, L. S., Leite-Filho, R. V., Panziera, W., Bandinelli, M. B., Sonne, L., Driemeier, D. \& Pavarini, S. P. (2019) Feline lymphoma in the nervous system: pathological, immunohistochemical, and etiological aspects in 16 cats. Pesquisa Veterinária Brasileira, 39, 393-401.

Mota, L. P., Kirchensch, C. L., Neto, A. L. C., Silva, J. C. S., Poty, J. A. C., Pompeu, J. G. F., Aleluia, R. G. G., da Silva, M. S., Fé, R. C. M., da Silva, L. E. B., Neto, E. A. C., Mesquita, N. P., abelo, M. N., Vasconcelos, A. C. A. B., Esperandio, J. V. M., Sousa, M. R. L., Pereira, S. A. (2021) Associação da síndrome da imunodeficiência humana com o linfoma de não Hodgkin. Research, Society and Development, 10(5), 1-10.

Pereira, P. R., Tagliari, N. J., Leite-Filho, R. V., Schaefer, G. D. C., Costa, F. V. A. D. \& Pavarini, S. P. (2017) Facial nerve ganglioneuroblastoma in a feline leukemia virus-positive cat. Ciência Rural, 47(5), 1-5.

Pereira A. S., Shitsuka, D. M., Parreira, F. J. \& Sitsuka, R. (2018). Metodologia da pesquisa científica. UFSM.

Radford, A. D., Addie, D., Belák, S., Boucraut-Baralon, C., Egberink, H., Frymus, T. \& Lutz, H. (2009) Feline calicivirus infection: ABCD guidelines on prevention and management. Journal of Feline Medicine and Surgery, 11(7), 556-564.

Samuelson, D. A., Andresen, T. L. \& Gwin, R. M. (1984) Conjunctival fungal flora in horses, cattle, dogs, and cats. Journal of the American Veterinary Medical Association, 184(10), 1240-1242.

Sila, G. H. \& Davidson, H. J. (2011) Eyelid diseases and surgery. In: G. Norsworthy, M. A. Crystal, S. F. G., Magric \& L. P. Tilley (Ed.), The Feline Patient (4th ed., pp. 171-174). New Jersey: Willey Blackwell.

Souza, J. O. T., Ângelo, F. F. \& Homem, L. A. S. (2010) Microbiota bacteriana conjuntival de felinos domésticos (Felis S. catus, Linnaeus, 1758) sadios da cidade de Juiz de Fora-MG. Revista Científica Eletrônica de Medicina Veterinária, 8(15), 1-14.

Sykes, J. E. \& Hartmann, K. (2014) Feline leukemia virus infection. In J. E. Sykes (Ed), Canine and feline infectious diseases (p. 224). Saunders.

Sykes, J. E. (2014) Feline immunodeficiency virus infection. In J. E. Sykes (Ed), Canine and feline infectious diseases (p. 209). Saunders.

Taylor, S. S., Goodfellow, M. R., Browne, W. J., Walding, B., Murphy, S., Tzannes, S. \& Dobson, J. M. (2009). Feline extranodal lymphoma: response to chemotherapy and survival in 110 cats. Journal of Small Animal Practice, 50(11), 584-592.

Teixeira, B. M., Taniwaki, S. A., Menezes, P. M. M., Rodrigues, A. K. P. P., Mouta, A. N., Arcebispo, T. L. M. \& Silva, M. X. (2019) Feline immunodeficiency virus in Northern Ceará, Brazil. Journal of Feline Medicine and Surgery Open Reports, 5(2), 1-7.

Vail, D. M. (2007). Feline lymphoma and leukemia. In D. M. Vail \& S. J. Withrow (Eds), Withrow and Macewen's small animal clinical oncology. (4th ed., pp. 31-50). Missouri: Saunders Elsevier.

Vail, D. M. (2013) Feline lymphoma and leukemia. In: S. J. Withrow, D. M. Vail \& R. L. Page, Withrow and MacEwen's small animal clinical oncology (5th ed., pp. 638-648). Philadelphia: Saunders.

Valli, V. E., Bienzle, D., Meuten, D. J. \& Linder, K. E. (2017) Tumors of the hemolymphatic system. Tumors in domestic animals, 5, $203-321$.

Zanutto, M. S., Froes, T. R., Teixeira, A. L. \& Hagiwara, M. K. (2011) Características clínicas da fase aguda da infecção experimental de felinos pelo vírus da imunodeficiência felina. Pesquisa Veterinária Brasileira, 31(3): 255-260. 